\title{
Temperature and Pseudobulb Size Influence Flowering of Odontioda Orchids
}

\author{
Matthew G. Blanchard ${ }^{1,3}$ and Erik S. Runkle ${ }^{2}$ \\ Department of Horticulture, Michigan State University, A288 PSSB, East \\ Lansing, MI 48824
}

Additional index words. base temperature, degree days, Odontoglossum alliance

\begin{abstract}
Odontioda is a cool-growing, sympodial epiphytic genus of orchids originating from the Andes Mountains of South America. Several hybrids are commercially grown as potted flowering plants for their brightly colored flowers and compact growth habit. We quantified how constant and fluctuating day/night temperatures influenced inflorescence initiation, time from visible inflorescence (VI) to flower, and pseudobulb development. Odontioda George McMahon 'Fortuna' and Lovely Penguin 'Emperor' were grown at constant temperature set points of $14,17,20,23,26$, or $29^{\circ} \mathrm{C}$ and day/night (12 $\mathrm{h} / 12 \mathrm{~h}$ ) temperatures of $20 / 14,23 / 17,26 / 14,26 / 20,29 / 23$, or $29 / 17^{\circ} \mathrm{C}$. Plants were grown in glass greenhouses under a 12-h photoperiod and a maximum irradiance of 500 $\mu \mathrm{mol} \cdot \mathrm{m}^{-2} \cdot \mathrm{s}^{-1}$. Within 6 weeks, heat stress symptoms such as leaf necrosis were observed on plants grown at a day temperature of $26^{\circ} \mathrm{C}$ or greater regardless of the night temperature. After 20 weeks, $90 \%$ or greater of both clones had a VI when grown at a constant temperature of 14 or $17^{\circ} \mathrm{C}$. Plants grown at a constant temperature of $17^{\circ} \mathrm{C} \mathrm{had}$ the greatest pseudobulb diameter with a mean increase of 3.5 to $4.0 \mathrm{~cm}$. In all treatments, a minimum pseudobulb diameter was required for uniform inflorescence initiation; pseudobulbs with a diameter of $5.5 \mathrm{~cm}$ or greater developed a VI in $93 \%$ of plants. Data for time from VI to open flower were converted to a rate, and a thermal-time model relating temperature with inflorescence development was developed. The base temperature and thermal time for VI to flower in George McMahon 'Fortuna' and Lovely Penguin 'Emperor' were estimated at $-0.1^{\circ} \mathrm{C}$ and $1429^{\circ} \mathrm{C} \cdot \mathrm{d}^{-1}$ and $0.8^{\circ} \mathrm{C}$ and $1250{ }^{\circ} \mathrm{C} \cdot \mathrm{d}^{-1}$, respectively. This information could be used by commercial orchid growers to assist in producing potted flowering Odontioda orchids for specific market dates.
\end{abstract}

Orchids are the second most valuable potted flowering plant in the United States with a reported wholesale value of $\$ 123$ million in 2006, an increase of $162 \%$ in the past decade (U.S. Department of Agriculture, 2007). In 2006, 14.7 million potted orchids were sold with a mean wholesale unit value of $\$ 8.32$ (U.S. Department of Agriculture, 2007). Among all the orchid genera sold within the United States, Phalaenopsis and related genera compose an estimated $85 \%$ to $90 \%$ of the potted orchid sales (Nash, 2003). However, as the production of Phalaenopsis orchids increases, commercial producers are looking for additional orchid genera that can be grown and sold at mass markets.

\footnotetext{
Received for publication 11 Feb. 2008. Accepted for publication 18 Mar. 2008.

We gratefully acknowledge funding by Michigan's plant agriculture initiative at Michigan State University (Project GREEEN), the Fred C. Gloeckner Foundation, the Michigan Agricultural Experiment Station, and greenhouse growers providing support for Michigan State University floriculture research. We also thank Dr. Donald Garling for his contributions to the manuscript and Mike Olrich for his greenhouse assistance.

${ }^{1}$ Graduate student.

${ }^{2}$ Associate Professor and extension specialist.

${ }^{3}$ To whom reprint requests should be addressed; e-mailmgblanch@msu.edu
}

The ability for commercial greenhouse growers to schedule potted plants into flower during periods of high demand (e.g., holidays) requires knowledge of environmental characteristics that regulate flowering. Temperature has been reported to control flowering in several orchid genera such as Dendrobium (Rotor, 1952), Miltoniopsis (Lopez and Runkle, 2006b), Phalaenopsis (Blanchard and Runkle, 2006; Sakanishi et al., 1980), and Zygopetalum (Lopez et al., 2003). For example, in Dendrobium nobile Lindley, plants grown at $18{ }^{\circ} \mathrm{C}$ remained vegetative, whereas those grown at $13{ }^{\circ} \mathrm{C}$ flowered regardless of photoperiod (Rotor, 1952). Similarly, plants of Zygopetalum Redvale 'Fire Kiss' had the highest flowering percentages when grown under a 9 -h photoperiod followed by 8 weeks of cooling at 11 or $14{ }^{\circ} \mathrm{C}$ (Lopez et al., 2003). The promotion of flowering in these orchid genera by exposure to low temperature suggests that flowering in other orchid species could also be regulated by temperature.

Odontioda orchids are intergeneric hybrids that are classified into the Odontoglossum alliance (Rittershausen and Rittershausen, 2003). These intergeneric hybrids were first created in the early 1800 s by breeders in Europe who crossed two genera, Odontoglossum H.B.K. and Cochlioda Lindl. (Carpenter, 2000). The genus Odontoglossum is composed of 54 species that are native to humid mountainous regions (1500 to 3200 $\mathrm{m})$ of South America, whereas the genus Cochlioda is composed of only seven species that are native to humid forests of the Andes Mountains (1700 to $3350 \mathrm{~m}$ ) of Bolivia, Columbia, Ecuador, and Peru (Baker and Baker, 2006).

Odontioda are sympodial epiphytic orchids and produce green pseudobulbs that have an apical pair of long narrow leaves and a shorter pair of leaves that arise from the base of the pseudobulb (Rittershausen and Rittershausen, 2003). Similar to other sympodial orchid genera, inflorescence primordia are initiated in the axils' leaf sheaths at the base of pseudobulbs (Goh et al., 1982). Odontioda hybrids have been selected by breeders for their bright and showy flowers and are available in many color combinations and patterns (Rittershausen and Rittershausen, 2003). They can be appealing potted plants because of their compact growth habit (30 to $45 \mathrm{~cm}$ ), erect to arching colorful inflorescences, and long-lasting flowers (up to 30 d) (Carpenter, 2000; Rittershausen and Rittershausen, 2003).

Odontioda hybrids are generally considered among orchid hobbyists to perform best at night temperatures ranging from 7 to $13^{\circ} \mathrm{C}$ and day temperatures between 24 and $27^{\circ} \mathrm{C}$ (Miller, 1992; Rohrl, 2005). Kubota et al., (2005) reported that plants grown at $18 / 8{ }^{\circ} \mathrm{C}$ or $23 / 13{ }^{\circ} \mathrm{C}(12-\mathrm{h}$ day/12-h night) for 54 weeks had visible inflorescence (VI) percentages of $7 \%$ and $50 \%$, respectively. A diurnal temperature fluctuation has also been suggested to improve vigor and plant performance (Miller, 1992; Rohrl, 2005), although to our knowledge, there is no scientific literature to support these observations. The growth of Odontioda orchids at cool temperatures suggests that they could be an appealing crop to produce in temperate climates where energy for heating is a significant greenhouse production cost (Bartok, 2001). However, to our knowledge, no scientific information has been published on the environmental flowering requirements for Odontioda.

The objectives of this study were 1) to determine how constant and fluctuating day and night temperatures influence flower initiation and pseudobulb development, and 2) to quantify how temperature controls time from VI to flowering in two Odontioda hybrids.

\section{Materials and Methods}

Plant material. In June 2003, mericloned plants of Odontioda George McMahon 'Fortuna' (Odontoglossum Parade $\times$ Odontioda Golden Rialto) and Odontioda Lovely Penguin 'Emperor' (Odontioda Lovely Morning $\times$ Odontioda Strawberry) were transplanted into $11-\mathrm{cm}$ round pots $(0.6-\mathrm{L}$ volume) in medium containing $75 \%$ fine-grade composted Douglas fir [Pseudotsuga menziesii (Mirb.) Franco] bark, 15\% medium-grade perlite, and $10 \%$ sphagnum peat (by volume) and grown in a commercial greenhouse in 
California. Plants were grown at $24 / 18{ }^{\circ} \mathrm{C}$ (day/night) under a natural photoperiod (lat. $37^{\circ} \mathrm{N}$ ) and a maximum photosynthetic photon flux $(P P F)$ of $500 \mu \mathrm{mol} \cdot \mathrm{m}^{-2} \cdot \mathrm{s}^{-1}$. On 22 Sept. 2003, 240 plants were received in East Lansing, MI, and were subsequently grown for 10 weeks in a glass-glazed greenhouse at a mean daily temperature (MDT) of $22.3^{\circ} \mathrm{C}$. The photoperiod was a constant $16 \mathrm{~h}(0600$ to $2200 \mathrm{HR}$ ) consisting of natural photoperiods (lat. $43^{\circ} \mathrm{N}$ ) with day-extension lighting provided by high-pressure sodium (HPS) lamps delivering a $P P F$ of 20 to $25 \mu \mathrm{mol} \cdot \mathrm{m}^{-2} \cdot \mathrm{s}^{-1}$ at plant height [as measured with a line quantum sensor (Apogee Instruments, Logan, UT)]. Light transmission was reduced with woven shade curtains (OLS 50; Ludvig Svensson, Charlotte, NC) and whitewash applied to the greenhouse glazing so that the maximum $P P F$ at plant height was 300 $\mu \mathrm{mol} \cdot \mathrm{m}^{-2} \cdot \mathrm{s}^{-1}$.

Plant culture. Plants were irrigated as necessary with reverse osmosis water supplemented with a water-soluble fertilizer providing $\left(\mathrm{mg} \cdot \mathrm{L}^{-1}\right): 125 \mathrm{~N}, 12 \mathrm{P}, 100 \mathrm{~K}, 65 \mathrm{Ca}$, $12 \mathrm{Mg}, 1.0 \mathrm{Fe}$ and $\mathrm{Cu}, 0.5 \mathrm{Mn}$ and $\mathrm{Zn}, 0.3 \mathrm{~B}$, and 0.1 Mo (MSU Special; Greencare Fertilizers, Chicago, IL). In Year 2, all plants were transplanted into the same size pot in a medium consisting of $80 \%$ medium-grade composted Douglas fir bark (Rexius Forest By-Products, Eugene, OR), 10\% long-fiber Canadian sphagnum moss (Mosser Lee Co., Millston, WI), and 10\% medium-grade perlite (Therm-O-Rock, Inc., New Eagle, PA) (by volume).

Temperature treatments. Ten plants of each Odontioda clone were placed in each of 12 glass greenhouse sections with constant temperature set points of $14,17,20,23,26$,

Table 1. Mean daily light integral $\left(\mathrm{mol} \cdot \mathrm{m}^{-2} \cdot \mathrm{d}^{-1}\right)$ at plant level per 4-week period during experiment for Year 1 (1 Dec. 2003 to 7 May 2004) and Year 2 (26 Oct. 2004 to 12 June 2005).

\begin{tabular}{lccccccc}
\hline & \multicolumn{7}{c}{ 4-week period } \\
\cline { 2 - 8 } Yr & 1 & 2 & 3 & 4 & 5 & 6 & 7 \\
\hline 1 & 3.8 & 3.9 & 5.2 & 5.9 & 6.3 & 8.8 & $\overline{-}^{2}$ \\
2 & 4.1 & 3.6 & 3.9 & 4.8 & 7.1 & 9.0 & 8.0 \\
\hline
\end{tabular}

${ }^{\mathrm{z}}$ Data not collected.

Table 2. Actual mean air temperatures of each temperature treatment in Years 1 and $2{ }^{\mathrm{z}}$

\begin{tabular}{lcc}
\hline Day/night temp & \multicolumn{2}{c}{ Actual day/night temp $\left({ }^{\circ} \mathrm{C}\right)$} \\
\cline { 2 - 3 } set point $\left({ }^{\circ} \mathrm{C}\right)$ & Yr 1 & Yr 2 \\
\hline $14 / 14$ & $15.1 / 14.4$ & $14.2 / 13.7$ \\
$17 / 17$ & $17.6 / 17.3$ & $17.6 / 16.9$ \\
$20 / 20$ & $20.0 / 20.0$ & $20.5 / 20.0$ \\
$23 / 23$ & $24.4 / 22.4$ & $23.1 / 22.4$ \\
$26 / 26$ & $25.8 / 26.1$ & - \\
$29 / 29$ & $29.1 / 29.4$ & - \\
$20 / 14$ & $20.0 / 13.8$ & $19.4 / 14.1$ \\
$23 / 17$ & $21.4 / 16.2$ & $22.3 / 17.1$ \\
$26 / 14$ & $25.2 / 14.3$ & - \\
$26 / 20$ & $25.7 / 19.4$ & - \\
$29 / 17$ & $27.4 / 17.0$ & - \\
$29 / 23$ & $28.4 / 22.8$ & - \\
\hline
\end{tabular}

${ }^{\mathrm{z}}$ The duration of the day and night temperature set points was $12 \mathrm{~h}$.

${ }^{\mathrm{y}}$ Treatment not used in Year 2. or $29{ }^{\circ} \mathrm{C}$ or fluctuating day/night $(12 \mathrm{~h} / 12 \mathrm{~h})$ temperature set points of $20 / 14,23 / 17,26 / 14$, $26 / 20,29 / 17$, or $29 / 23^{\circ} \mathrm{C}$. In Year 2 , constant temperature set points of 26 and $29^{\circ} \mathrm{C}$ and day/night temperature set points of $26 / 14$, $26 / 20,29 / 17$, and $29 / 23{ }^{\circ} \mathrm{C}$ were not used because heat stress symptoms were observed on plants grown at these temperatures in Year 1. Temperature set points were maintained by an environmental computer (Priva CD750; Vineland Station, Ontario, Canada) that controlled roof vents, exhaust fans, evaporative cooling, and heating as needed. The photoperiod was maintained at $12 \mathrm{~h}$ for 20 weeks by pulling opaque black cloth from 1700 to $0800 \mathrm{HR}$ and was extended with light from incandescent lamps ( 3 to $4 \mu \mathrm{mol} \cdot \mathrm{m}^{-2} \cdot \mathrm{s}^{-1}$ at plant height). The photoperiod and skotoperiod paralleled the day and night temperature set points, respectively. After 20 weeks and until the end of each replication, plants remained in the temperature treatments, but the photoperiod was a constant $16 \mathrm{~h}(0600$ to $2200 \mathrm{HR}$ ) consisting of natural daylength, with day-extension lighting provided by HPS lamps delivering a $P P F$ of 50 to 75 $\mu \mathrm{mol} \cdot \mathrm{m}^{-2} \cdot \mathrm{s}^{-1}$ at plant height. A vapor-pressure deficit of $0.9 \mathrm{kPa}$ was maintained at each

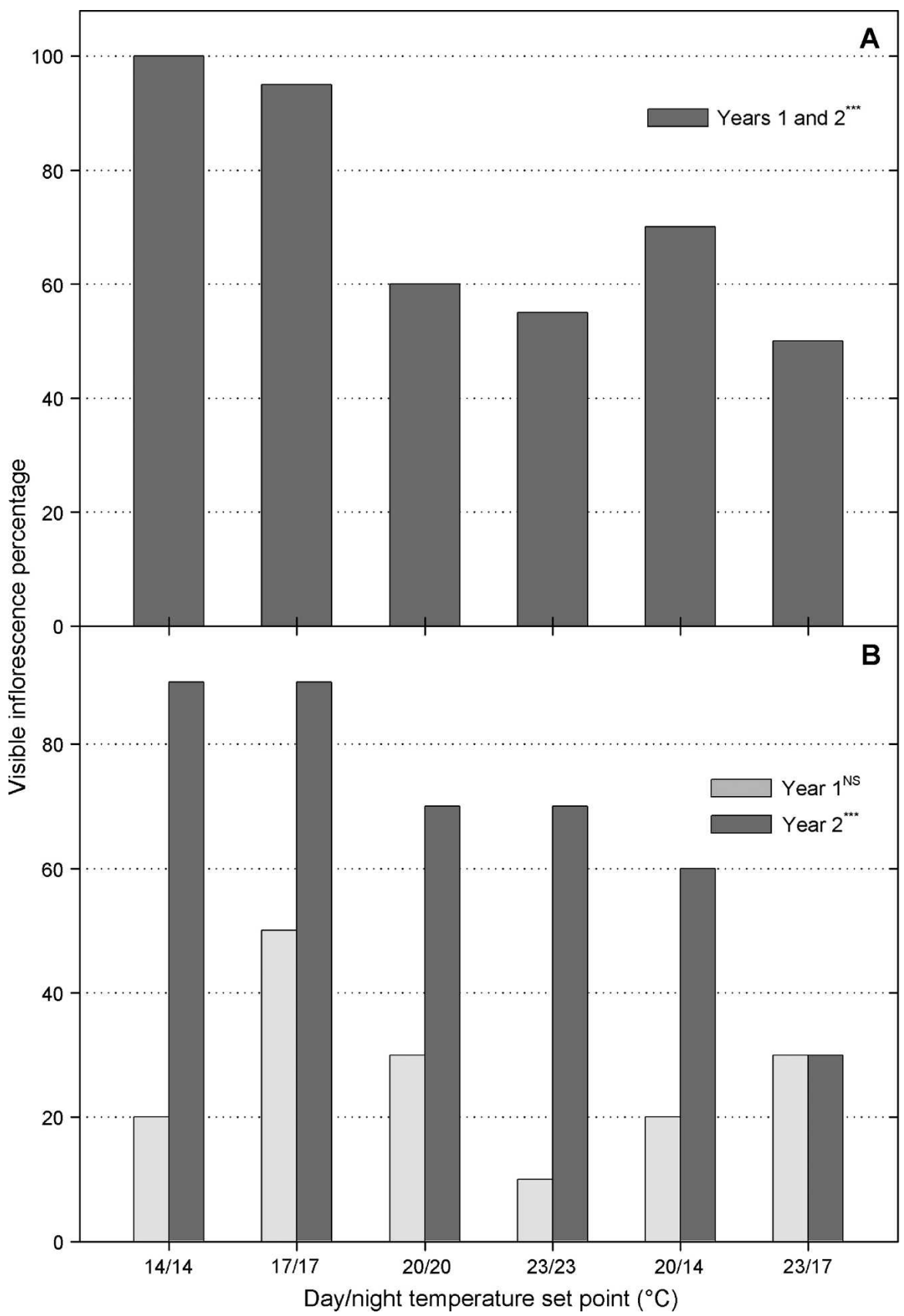

Fig. 1. Visible inflorescence (VI) percentages for (A) Odontioda George McMahon 'Fortuna' and (B) Odontioda Lovely Penguin 'Emperor' after 20 weeks at constant temperature set points of 14, 17, 20, or $23{ }^{\circ} \mathrm{C}$ and fluctuating day/night temperature set points of $20 / 14$ or $23 / 17^{\circ} \mathrm{C}$. The day and night were $12 \mathrm{~h}$ each. VI percentages were analyzed using a binomial distribution with logit transformation. Data for George McMahon 'Fortuna' were pooled for Years 1 and 2 because there was no significant difference between years. ${ }^{\text {Ns, }}{ }^{* * *}$ Nonsignificant or significant at $P \leq 0.001$. 
temperature treatment during the skotoperiod by the injection of water vapor. Light transmission through the greenhouse was reduced as previously described. The mean daily light integral per 4-week period during the experiment was between 3.6 and $9.0 \mathrm{~mol} \cdot \mathrm{m}^{-2} \cdot \mathrm{d}^{-1}$ (Table 1).

Air temperature was measured in each greenhouse section by aspirated thermocouples $(0.127-\mathrm{mm}$ type E) every $10 \mathrm{~s}$ and hourly means were recorded by a data logger (CR10; Campbell Scientific, Logan, UT). Temperature control during the experiment was within $\pm 1.6{ }^{\circ} \mathrm{C}$ of the greenhouse temperature set points for all treatments in both years (Table 2).

The experiment was replicated in time beginning on 1 Dec. 2003 (Year 1) and on 26 Oct. 2004 (Year 2). In each year, plants were assigned randomly to each of the temperature treatments. After completion of the first replication and until the beginning of the second replication, plants were transferred to a common glass-glazed greenhouse with an MDT of $21.9^{\circ} \mathrm{C}$ and a constant $16-\mathrm{h}(0600$ to $2200 \mathrm{HR}$ ) photoperiod consisting of natural daylengths with day-extension lighting provided by HPS lamps delivering a $P P F$ of 25 to $50 \mu \mathrm{mol} \cdot \mathrm{m}^{-2} \cdot \mathrm{s}^{-1}$ at plant height. Between the first and second replication, the maximum $P P F$ at plant height was maintained at 300 $\mu \mathrm{mol} \cdot \mathrm{m}^{-2} \cdot \mathrm{s}^{-1}$ as previously described. Plants that displayed symptoms of heat stress in Year 1 were not used in Year 2.

Data collection. The date of first VI without dissection (less than $0.3 \mathrm{~cm}$ ) and the date that the first flower opened were recorded for each plant. Days to VI, days from VI to open flower, days to open flower, VI percentage, and inflorescence abortion percentage were calculated for each treatment. The total number of VIs and the number of flower buds and flowers on the first VI were recorded for each plant. On the date of flowering, total inflorescence length from emergence to the tip of the inflorescence was measured. In both years, plants that did not have a VI after 20 weeks of the onset of treatments were considered not reproductive.

In Year 2 at the beginning of the experiment, one pseudobulb on each plant was selected and the leaf length and pseudobulb diameter were measured. Pseudobulbs were selected if they had no VI, had not previously initiated an inflorescence, and if the epidermis was not shriveled. In general, only one pseudobulb per plant met these criteria. Leaf length was measured from the base of the pseudobulb to the tip of the longest extended leaf. Pseudobulb diameter was measured at the widest point of the pseudobulb from the outer edge of a basal leaf to the outer edge of the opposing leaf by using a digital caliper. Leaf length and pseudobulb diameter were measured again when each plant flowered or after 31 weeks of temperature treatments for plants that did not have a VI. The increase in pseudobulb diameter and the leaf length was calculated.

Statistical analysis. A completely randomized block design was used in each year.

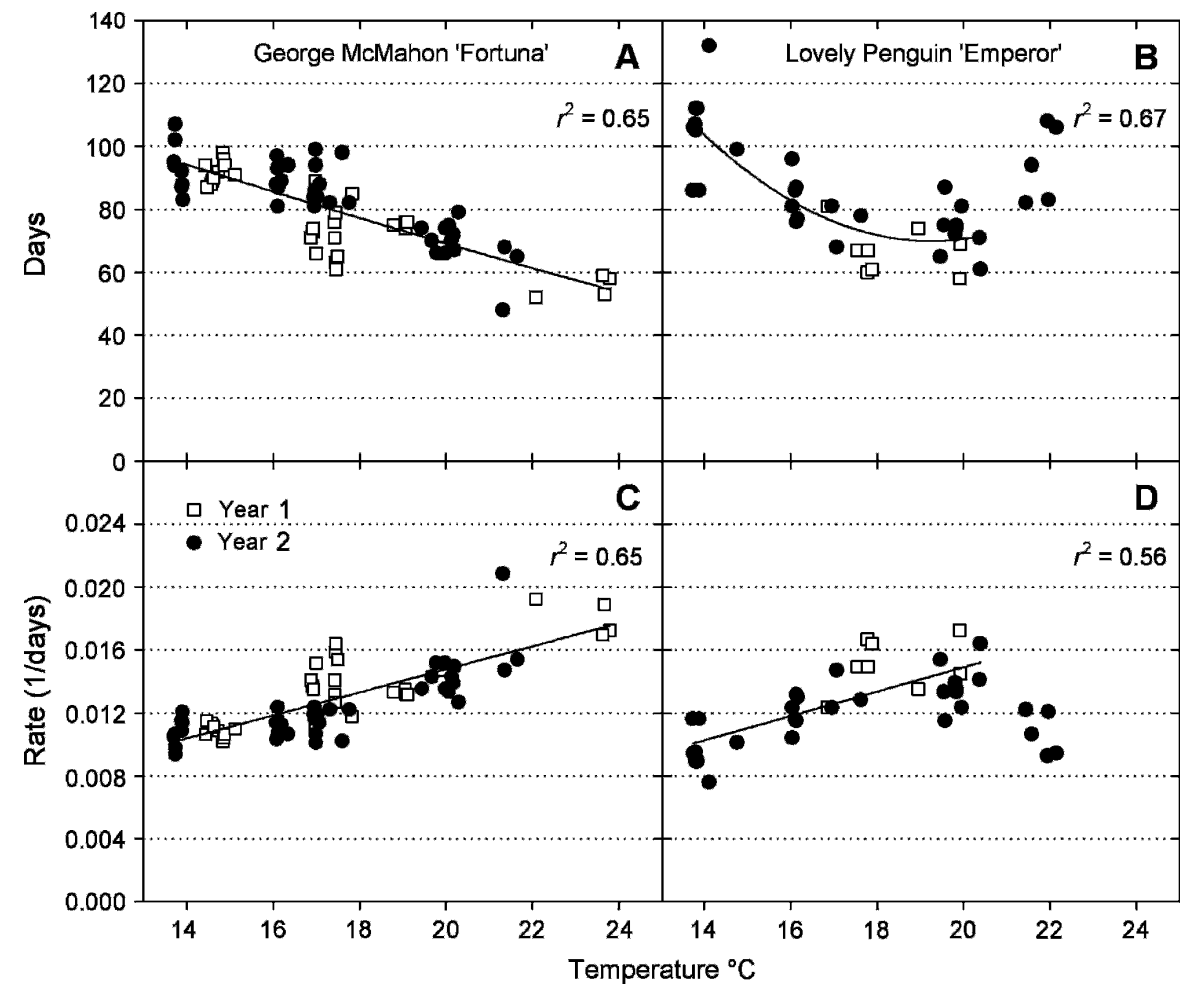

Fig. 2. Effect of temperature on time from visible inflorescence to flower (A and $\mathbf{B}$ ) and rate of progress to flower (C and $\mathbf{D})$ in two Odontioda clones. Each symbol represents an individual plant. The solid lines represent the regression equation using pooled data for Years 1 and 2. Data points greater than $20.4{ }^{\circ} \mathrm{C}$ for Lovely Penguin 'Emperor' were judged to be supraoptimal and were not included in the regression analysis. The mean daily temperature was reported for treatments with a fluctuating day and night temperature. Parameters of linear regression analysis in $\mathbf{C}$ and $\mathbf{D}$ are presented in Table 3.

Table 3. Parameters of linear regression analysis relating temperature to rate of progress for time from visible inflorescence to flower in Odontioda George McMahon 'Fortuna' and Odontioda Lovely Penguin 'Emperor'.

\begin{tabular}{lccccr}
\hline Odontioda clone & $\begin{array}{c}\text { Temperature } \\
\left({ }^{\circ} \mathrm{C}\right)\end{array}$ & $\begin{array}{c}\text { Intercept }\left(\mathrm{b}_{0}\right) \\
(1 / \text { days })\end{array}$ & $\begin{array}{c}\text { Slope }\left(\mathrm{b}_{1}\right) \\
(1 / \text { days }) /{ }^{\circ} \mathrm{C}\end{array}$ & $\begin{array}{c}\mathrm{T}_{\mathrm{b}} \\
\left({ }^{\circ} \mathrm{C}\right)\end{array}$ & ${ }^{\circ} \mathrm{C} \cdot \mathrm{d}^{-1}$ \\
$\begin{array}{l}\text { George McMahon } \\
\quad \text { Fortuna }\end{array}$ & 13.7 to 23.8 & $1.0 \mathrm{E}-4 \pm 1.1 \mathrm{E}-3^{\mathrm{y}}$ & $7.0 \mathrm{E}-4 \pm 6.4 \mathrm{E}-5$ & -0.1 & 1429 \\
$\begin{array}{c}\text { Lovely Penguin } \\
\text { Emperor }\end{array}$ & 13.7 to 20.4 & $-6.0 \mathrm{E}-4 \pm 2.0 \mathrm{E}-3$ & $8.0 \mathrm{E}-4 \pm 1.0 \mathrm{E}-4$ & 0.8 & 1250 \\
\hline
\end{tabular}

${ }^{2}$ The slope $\left(b_{1}\right)$ and intercept $\left(b_{0}\right)$ were used to calculate the base temperature $\left(T_{b}\right)$ and degree-days $\left({ }^{\circ} \mathrm{C} \cdot \mathrm{d}^{-1}\right)$

${ }^{y} \mathrm{SE}$.

Data were analyzed using a statistical analysis software (SAS; SAS Institute, Cary, NC) mixed-model procedure (PROC MIXED), and pairwise comparisons between treatments were performed using Tukey's honestly significant difference test. VI percentages were analyzed by using the generalized model procedure (PROC GENMOD) with a binomial distribution and logit transformation. Pearson correlation coefficients were determined for the relationship between final pseudobulb diameter and the occurrence of VI for each plant using the correlation procedure (PROC CORR). For each Odontioda clone, rates of progress toward flowering were modeled as a function of the calculated MDT for each plant from the date of VI to the date of flowering. Data for time from VI to flower were converted to rates by calculating the reciprocal (1/days), and linear regression analysis was performed in Sigma Plot (SPSS,
Chicago, IL). The intercept $\left(b_{0}\right)$ and slope $\left(b_{1}\right)$ of the regression lines were used to estimate the base temperature $\left(\mathrm{T}_{\mathrm{b}}=-\mathrm{b}_{0} / \mathrm{b}_{1}\right)$ and the amount of thermal time (units of degree-days) that were required from VI to flower $\left({ }^{\circ} \mathrm{C} \cdot \mathrm{d}^{-1}=1 / \mathrm{b}_{1}\right)$ in each Odontioda clone (Roberts and Summerfield, 1987).

\section{Results}

During Year 1, plants of both clones displayed symptoms of heat stress (e.g., severe necrosis on leaf margins and apices) when grown at day/night temperature set points of 26/26, 29/29, 26/14, 26/20, 29/17, or $29 / 23{ }^{\circ} \mathrm{C}$. The percentage of plants that had a VI and days to VI were variable among plants in these treatments (data not presented). Furthermore, a high percentage of plants that initiated inflorescences during the temperature treatments aborted before 
flowering. Data from these treatments were not included in further analysis.

Visible inflorescence percentage. Temperature had a significant influence on the percentage of plants that initiated a VI and developed to flowering in George McMahon 'Fortuna' (Years 1 and 2) and Lovely Penguin 'Emperor' (Year 2) (Fig. 1). During Year 1, inflorescence initiation in Lovely Penguin 'Emperor' was variable and 50\% or less of plants initiated inflorescences in all treatments. After 20 weeks, $90 \%$ or greater of plants of George McMahon 'Fortuna' and Lovely Penguin 'Emperor' (Year 2 only) had a VI when grown at $14 / 14$ and $17 / 17{ }^{\circ} \mathrm{C}$. Inflorescence abortion was not observed on any plants grown at a day temperature $23{ }^{\circ} \mathrm{C}$ or less in both years regardless of the night temperature.

Time to visible inflorescence and flower. Temperature had no influence on time to VI in both Odontioda clones and varied among treatments from a mean of 52 to $86 \mathrm{~d}$ (data not presented). Days from VI to flower in George McMahon 'Fortuna' decreased with increasing MDT until $\approx 24{ }^{\circ} \mathrm{C}$, whereas it decreased with increasing MDT only until $\approx 20{ }^{\circ} \mathrm{C}$ in Lovely Penguin 'Emperor' (Fig. 2). For example, as MDT increased from 14 to $23{ }^{\circ} \mathrm{C}$, time from VI to flower in George McMahon 'Fortuna' decreased from 93 to 58 d. Similarly, an increase in temperature from 14 to $20^{\circ} \mathrm{C}$ reduced time from VI to flower in Lovely Penguin 'Emperor' from 105 to $72 \mathrm{~d}$.

The rate of progress from VI to flower was linear for both George McMahon 'Fortuna' and Lovely Penguin 'Emperor' within the measured MDT ranges of 13.7 to $23.8^{\circ} \mathrm{C}$ and 13.7 to $20.4{ }^{\circ} \mathrm{C}$, respectively (Fig. 2). Flower development was delayed in Lovely Penguin 'Emperor' when grown at temperatures above $20.4^{\circ} \mathrm{C}$. In George McMahon 'Fortuna', the base temperature for the rate of development from VI to first open flower was calculated as $-0.1{ }^{\circ} \mathrm{C}$ and thermal time for completion of the event was estimated at $1429{ }^{\circ} \mathrm{C} \cdot \mathrm{d}^{-1}$ (Table 3 ). The base temperature and thermal time from VI to flower in Lovely Penguin 'Emperor' were calculated to be $0.8^{\circ} \mathrm{C}$ and $1250{ }^{\circ} \mathrm{C} \cdot \mathrm{d}^{-1}$, respectively.

Inflorescence characteristics. There was no clear trend in the effect of temperature on inflorescence number and plants of both clones had a mean of $1.2 \pm 0.3$ inflorescences (data not presented). There were no differences among treatments in the number of flower buds on the first VI, and means were 8.9 and 7.4 for George McMahon 'Fortuna' and Lovely Penguin 'Emperor', respectively (data not presented). The total inflorescence length at flower was not significantly influenced by temperature in George McMahon 'Fortuna' and Lovely Penguin 'Emperor', and means were 26.8 and $35.0 \mathrm{~cm}$, respectively (data not presented).

Pseudobulb diameter and leaf length. Temperature had a significant influence on the increase in pseudobulb diameter $(P \leq$ $0.01)$ and the final pseudobulb diameter $(P \leq$ $0.001)$ of both Odontioda clones (Fig. 3). As the day temperature increased from 14

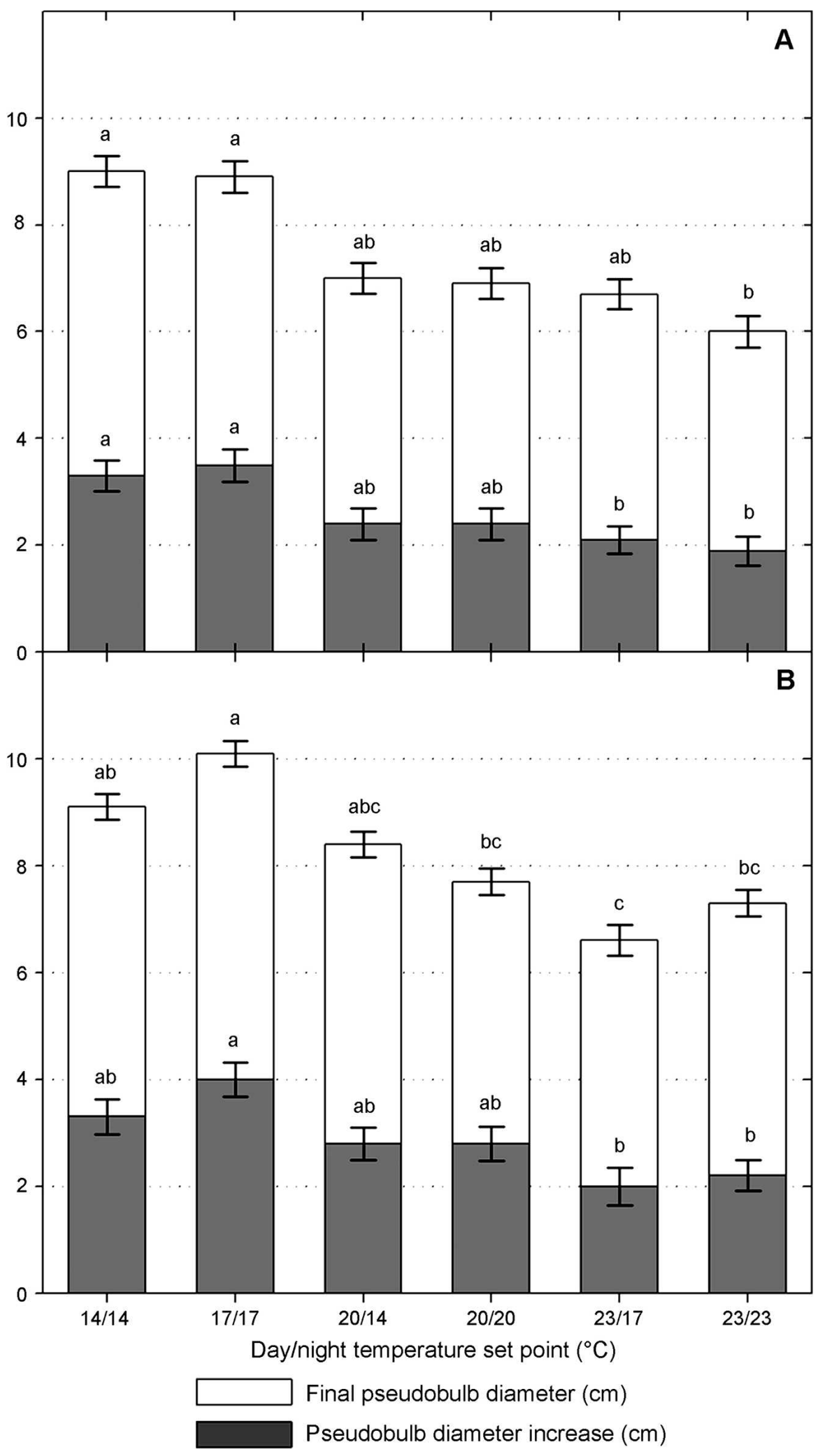

Fig. 3. Influence of temperature on final pseudobulb diameter and pseudobulb diameter increase in (A) Odontioda George McMahon 'Fortuna' and (B) and Odontioda Lovely Penguin 'Emperor' at constant temperature set points of $14,17,20$, or $23^{\circ} \mathrm{C}$ and fluctuating day/night temperature set points of $20 / 14$ or $23 / 17^{\circ} \mathrm{C}$. The day and night were $12 \mathrm{~h}$ each. Vertical bars indicate sEs of treatment means. Mean separation within species and variable by Tukey's honestly significant difference test at $P \leq 0.05$.

to $23{ }^{\circ} \mathrm{C}$, pseudobulb diameter generally decreased. In both clones, plants grown at a constant temperature of $17{ }^{\circ} \mathrm{C}$ had a greater pseudobulb diameter increase than plants grown at $23 / 23$ or $23 / 17{ }^{\circ} \mathrm{C}$ with a mean of 3.5 to $4.0 \mathrm{~cm}$. The occurrence of inflorescence initiation in all temperature treatments was positively correlated $(P \leq 0.01)$ to final 
pseudobulb diameter (Fig. 4). In George McMahon 'Fortuna' and Lovely Penguin 'Emperor', pseudobulbs with a diameter 3.5 or greater and $5.0 \mathrm{~cm}$ or greater, respectively, had developed a VI in $60 \%$ or more of plants. The increase in leaf length and the final leaf length were not significantly different among treatments, and final leaf lengths varied from 24.6 to $30.3 \mathrm{~cm}$ (data not presented).

\section{Discussion}

In this study, Odontioda grown at a day temperature of $26^{\circ} \mathrm{C}$ or higher developed leaf necrosis, and inflorescences aborted; thus, plants were determined to be of unacceptable quality for commercial sales. Therefore, to prevent high-temperature stress during commercial production, these temperatures are not recommended. Our observations are supported by a Kubota et al. (2005) study, in which all plants of Odontioda Marie Noel 'Velano' grown at $28 / 18{ }^{\circ} \mathrm{C}(12-\mathrm{h}$ day/12-h night) developed yellow leaves within 8 weeks and died within 24 weeks. A similar response to high temperature has been reported in the ladybird orchid, Zygopetalum Redvale 'Fire Kiss', in which flower buds on plants transferred to MDTs of 25.4 to $28.6{ }^{\circ} \mathrm{C}$ developed necrotic lesions and aborted within $20 \mathrm{~d}$ (Lopez and Runkle, 2004).

In both Odontioda clones, the percentage of plants that initiated an inflorescence and developed open flowers was greatest at a constant temperature of 14 or $17{ }^{\circ} \mathrm{C}$. A similar response to low temperature has been reported in another South American orchid genus, Miltoniopsis (Lopez and Runkle, 2006b). Plants of Miltoniopsis Augres

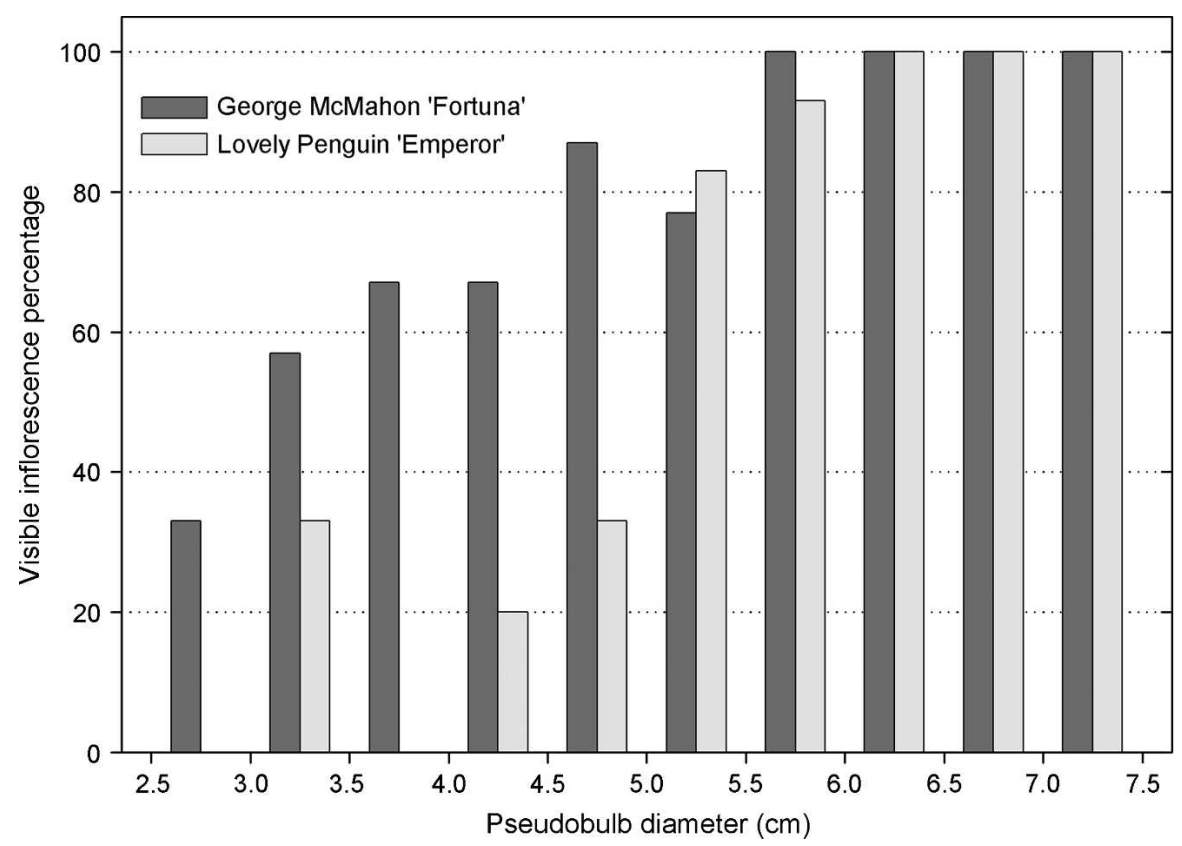

Fig. 4. Influence of pseudobulb diameter on visible inflorescence percentage in two Odontioda clones. Pseudobulb diameter was measured when each plant flowered or after 31 weeks of temperature treatments for plants that did not have a visible inflorescence (VI). Pearson correlation coefficients for the relationship between pseudobulb diameter and VI were $0.40(P \leq 0.01)$ and $0.58(P \leq 0.001)$ for George McMahon 'Fortuna' and Lovely Penguin 'Emperor', respectively. Data are for Year 2 only. mercial production, the ability to inhibit or promote flowering in a crop by manipulating the environment is desirable because it allows for precise crop scheduling and improved production efficiency. In Odontioda, a growing environment that promotes vegetative development and inhibits flowering would be beneficial because plants that flower prematurely require the removal of inflorescences or sorting, both of which are labor-intensive. Kubota et al. (2005) reported that no plants of Odontioda initiated inflorescences within 54 weeks when grown under a low light intensity $\left(150 \mu \mathrm{mol} \cdot \mathrm{m}^{-2} \cdot \mathrm{s}^{-1}\right.$ or less) and at $18 / 8$ or $23 / 13{ }^{\circ} \mathrm{C}$. These results collectively suggest that during production of Odontioda, flowering could be delayed or inhibited by growing plants at a day temperature of $23{ }^{\circ} \mathrm{C}$ and under a low light intensity. However, the effect of this environmental strategy on subsequent flowering in a favorable environment is unknown.

In this study, a minimum pseudobulb diameter was required for uniform inflorescence initiation; pseudobulbs with a diameter $5.5 \mathrm{~cm}$ or greater developed a VI in $93 \%$ of plants of both Odontioda clones. As with other flowering plants, a juvenility period exists in orchids in which a specific stage of maturity must be reached before plants are capable of reproductive development (Goh et al., 1982). The low VI percentages observed in Odontioda Lovely Penguin 'Emperor' during Year 1 could at least partially be attributed to plant immaturity.

Odontioda grown at the coolest constant temperatures of 14 or $17^{\circ} \mathrm{C}$ had the greatest increase in pseudobulb diameter and thus the greatest final pseudobulb diameter. Therefore, pseudobulb size could be a good tool for determining when a population of Odontioda plants is of adequate maturity for flower induction. Ichihashi (1997) reported that flower initiation in nobile-type Dendrobium orchids occurred on mature pseudobulbs only when they were exposed to temperatures of 7.5 to $20{ }^{\circ} \mathrm{C}$ (Ichihashi, 1997). In Miltoniopsis Augres 'Trinity', when pseudobulb diameter was $1.5 \mathrm{~cm}$ or less or $3.1 \mathrm{~cm}$ or greater, $27 \%$ and $90 \%$ of pseudobulbs initiated inflorescences, respectively, after vernalization (Lopez and Runkle, 2006a).

The time from VI to flower in Odontioda grown at $17{ }^{\circ} \mathrm{C}$ was considerably longer than the estimated time for Zygopetalum Redvale 'Fire Kiss' (39 d) but shorter than the estimated time for several Phalaenopsis hybrids (139 d) (Lopez and Runkle, 2004; Robinson, 2002). The mean time from VI to flower in Odontioda Lovely Penguin 'Emperor' at $23{ }^{\circ} \mathrm{C}$ was $23 \mathrm{~d}$ greater than plants grown at $20{ }^{\circ} \mathrm{C}$, which suggests that a constant temperature of $23{ }^{\circ} \mathrm{C}$ is supraoptimal for inflorescence development in this clone.

The calculated base temperatures of George McMahon 'Fortuna' and Lovely Penguin 'Emperor' during inflorescence development were similar: -0.1 and $0.8{ }^{\circ} \mathrm{C}$. These base temperatures are considerably lower than the temperatures used in this study, and further experiments at lower 
MDTs are needed to more precisely estimate their values. The estimated base temperature for Odontioda is $3.2{ }^{\circ} \mathrm{C}$ lower than the estimated base temperature of another native South American orchid genus, Zygopetalum (Lopez and Runkle, 2004). The lower base temperature in Odontioda could be attributed to the genetic background of these intergeneric clones. The predominant species in the background of Odontioda George McMahon 'Fortuna' and Lovely Penguin 'Emperor' is Odontoglossum crispum Lindl., which is native to high elevations (1800 to $3000 \mathrm{~m}$ ) of the Andes Mountains in Columbia (Baker and Baker, 2006; Wildcatt Orchids, 2004). In comparison, Zygopetalum is native to midelevations of 300 to $1500 \mathrm{~m}$ (Pridgeon, 2000).

In conclusion, Odontioda orchids should be grown at temperatures $26{ }^{\circ} \mathrm{C}$ or less to avoid heat stress and inflorescence abortion. Cool constant temperatures between 14 and $17{ }^{\circ} \mathrm{C}$ can be used to promote both inflorescence initiation and development in these two Odontioda clones. At this temperature range, pseudobulbs will attain a minimum size required for uniform flowering. Time from inflorescence initiation to flowering is related to the MDT and can be predicted with our model. This information could be used by commercial orchid growers when producing Odontioda orchids in flower for specific market dates.

\section{Literature Cited}

Baker, M.L. and C.O. Baker. 1991. Orchid species culture: Pescatorea, Phaius, Phalaenopsis, Pholidota, Phragmipedium, Pleione. Timber Press, Portland, OR.
Baker, M.L. and C.O. Baker. 2006. Orchid species culture: Oncidium/Odontoglossum alliance. Timber Press, Portland, OR.

Bartok J.W., Jr. 2001. Energy conservation for commercial greenhouses. Natural Resource, Agriculture, and Engineering Service Cooperative Extension, Ithaca, NY.

Blanchard, M.G. and E.S. Runkle. 2006. Temperature during the day, but not during the night, controls flowering of Phalaenopsis orchids. J. Expt. Bot. 57:4043-4049.

Carpenter, M.O. 2000. Oncidiinae intergenerics. Orchids 69:734-741.

Goh, C.J., M.S. Strauss, and J. Arditti. 1982 Flower induction and physiology in orchids, p. 213-241. In: Goh, C.J. (ed.). Orchid biology: Reviews and perspectives, II. Cornell Univ. Press, Ithaca, NY

Ichihashi, S. 1997. Orchid production and research in Japan, p. 171-212. In: Arditti, J. and A.M. Pridgeon (eds.). Orchid biology: Reviews and perspectives, VII. Kluwer Academic Publishers, Dordrecht, The Netherlands.

Kubota, S., J. Yamamoto, Y. Takazawa, H. Sakasai, K. Watanabe, K. Yoneda, and N. Matsui. 2005. Effects of light intensity and temperature on growth, flowering, and single-leaf $\mathrm{CO}_{2}$ assimilation in Odontioda orchid. J. Jpn. Soc. Hort. Sci. 74:330-336.

Lee, N. and G.M. Lin. 1987. Controlling the flowering of Phalaenopsis. p. 27-44. In: Chang, L.-R. (ed.). Proc. Symp. Forcing Cult Hort. Crops. Special Publ. 10. Taichung District Agr. Improvement Sta., Changhua, Taiwan, Republic of China.

Lopez, R.G. and E.S. Runkle. 2004. The effect of temperature on leaf and flower development and flower longevity of Zygopetalum Redvale 'Fire Kiss' orchid. HortScience 39: 1630-1634.

Lopez, R.G. and E.S. Runkle. 2006a. Effect of temperature and pseudobulb maturity on flowering of the orchid Miltoniopsis Augres 'Trin- ity’. Abstracts XXVII Intl. Hort. Congr., Seoul. p. 136 (abstr.).

Lopez, R.G. and E.S. Runkle. 2006b. Temperature and photoperiod regulate flowering of potted Miltoniopsis orchids. HortScience 41:593597.

Lopez, R.G., E.S. Runkle, R.D. Heins, and C.M. Whitman. 2003. Temperature and photoperiodic effects on growth and flowering of Zygopetalum Redvale 'Fire Kiss'. Orchids. Acta Hort. 624:155-162.

Miller, J. 1992. Odontoglossums. Amer. Orchid Soc. Bul. 61:334-339.

Nash, N. 2003. Phalaenopsis primer: A beginner's guide to growing moth orchids. Orchids 72:906-913.

Pridgeon, A. 2000. The illustrated encyclopedia of orchids. Timber Press, Portland, OR

Rittershausen, B. and W. Rittershausen. 2003. Growing orchids. Hermes House, London, UK.

Roberts, E.H. and R.J. Summerfield. 1987. Measurement and prediction of flowering in annual crops, p. 17-50. In: Atherton, J.G. (ed.). Manipulation of flowering. Butterworths, Kent, UK

Robinson, K.A. 2002. Effects of temperature on the flower development rate and morphology of Phalaenopsis orchid. Mich. State Univ., East Lansing. MS Thesis.

Rohrl, H. 2005. Odontoglossum hybrids. Orchids 74:604-608.

Rotor, G.B. 1952. Daylength and temperature in relation to growth and flowering of orchids. Cornell Univ. Agr. Expt. Sta. Bul. 885:3-47.

Sakanishi, Y., H. Imanishi, and G. Ishida. 1980. Effect of temperature on growth and flowering of Phalaenopsis amabilis. Bul. Univ. Osaka. Ser. B: Agr. Biol. 32:1-9.

U.S. Department of Agriculture. 2007. Floriculture crops 2006 summary. Agr. Stat. Board, Washington, DC.

Wildcatt Orchids. 2004. Wildcatt orchids Sept. 2004 database. Wildcatt Database Co., Ames, IA. 